\title{
HISTORIA DE LA COMUNIDAD ASHÁNINKA EL MILAGRO Y ESCUELA: HISTORIA ORAL Y MEMORIA
}

\author{
Jacobo Alva Mendo y Enrique Jacobo Díaz \\ Universidad Nacional Mayor de San Marcos-EILA \\ jacobo.alva@unmsm.edu.pe \\ (1) https://orcid.org/0000-0002-5711-4151 \\ enrique.jacobo@unmsm.edu.pe \\ (1) https://orcid.org/0000-0003-3383-2383
}

\section{Resumen}

Presenta una reflexión sobre la construcción de la historia de la comunidad asháninka E1 Milagro ubicada en el valle de Marankiari, distrito de Satipo en la selva central peruana, recogida por un docente originario del pueblo asháninka. Discute cuatro aspectos vinculados a la historia y la memoria, el primero está referido a las fuentes y la constitución en archivo oral en situaciones de subjetividad; el segundo, el análisis del documento reconstruido y presentado como historia de la comunidad; el tercero, el uso pedagógico de la historia reconstruida desde la memoria de originarios en el contexto de la demanda de una escuela rural caracterizada y bajo la égida de la política de Educación Intercultural Bilingüe; $y$ finalmente, unas notas desde los enfoques de la historia oral y la memoria que repiensan los tres procedimientos precedentes como objeto de análisis. 
Palabras claves: Asháninka; Historia de la comunidad nativa; Escuela EIB; Historia oral; Memoria

\begin{abstract}
This article is a reflection on the construction of the history of the Ashaninka community El Milagro located in the Marankiari valley, Satipo district in the central Peruvian Amazon, collected by a teacher who is a member of the Ashaninka people. It discusses four aspects related to the sources and the constitution of the oral archive in situations of subjectivity: analysis of the reconstructed document and presented as the history of the community; the pedagogical use of the reconstructed history based on the memory of the natives in the context of the demand for a characterized rural school and under the aegis of the bilingual intercultural education policy; and some notes from the oral history and memoryperspective that rethink the three preceding procedures as an object of analysis.
\end{abstract}

Keywords: Asháninka; History of the native community; EIB school; Oral history; Memory

\title{
1. El punto de partida de la historia
}

Este es un avance de investigación colaborativa ${ }^{1}$ que expone el diálogo entre Enrique, docente asháninka, y el suscrito, que acompaña y aprende a propósito de la indagación en torno a la historia de la comunidad y la enseñanza en la escuela. ${ }^{2}$ Son largas horas de conversación y de repensar los avances que se iniciaron el primer semestre de 2019, en dos años se han producido más preguntas que respuestas. Este texto desarrolla una reflexión sobre ¿qué aspectos se pueden consideran en la historia de la comunidad nativa contada por los comuneros y recogida por un "hermano" o "noshaninka" desde la historia oral y la memoria?

1 Esta comunicación forma parte de los avances del proyecto "El narrar en asháninka. La oralidad del río y escuela” (E21031271-UNMSM). Es el resultado de la interacción sobre la tesis de maestría en Educación Intercultural Bilingüe que viene desarrollando Enrique Jacobo y la asesoría de Jacobo Alva, ambos integrantes del grupo de investigación Discursos, Representaciones y Estudios Interculturales (EILA-UNMSM).

2 El aprendizaje sobre el valle de Marankiari se enriquece con el estudio en el valle de Tsiriari en el vecino distrito de Mazamari, emprendido en los últimos años. 
Un primer aspecto a considerar es que se trata de una comunidad "nativa”, denominada así desde la década de 1970 por ley nacional como signo diferenciador de la comunidad campesina del ámbito rural andino y de la costa, con relación al ámbito de la Amazonía. Es la historia de la comunidad nativa de la Amazonía peruana de la región de la selva central contada por los comuneros y recogida desde las preguntas e intereses de lo que desea que se narre como historia, una historia que explique los hechos vividos para que estos sucesos se enseñen en la escuela donde Enrique ejerce como docente.

Cuando Enrique fue consultado para que explique por qué quiere recuperar la historia de la comunidad nativa El Milagro, del cual él es originario, dijo: "Primero tenía la idea de escribir la historia de la comunidad. Tenía una idea de lo que me contaba mi papá y cómo vivía antes y lo que me llamó la atención es como se vivía ahora en El Milagro". Añade que "Fui a la comunidad para que me cuenten mis hermanos y otras personas que viven allí porque ellos saben, y lo preocupante es que no saben cómo es la historia de la comunidad. Decían no lo sé, busca al señor Germán”. Me aclaró con desazón: “Como veo que ellos están sumisos y no saben qué decir y hacer. No se preocupan cómo está y no saben cómo está la comunidad, de su situación, solo se dedican a trabajar en la chacra y no hay liderazgo".

Otra de las razones se mezcla con el conocimiento mismo que ha ido adquiriendo como hijo, nieto, padre y hermano de la comunidad:

Escuché de mi papá. Siempre ha vivido en El Milagro. Yo he nacido acá en la orilla del río, los colonizadores lo botaron "váyanse de acá" antes nadie nos decía que aquí vivíamos y había muchos animales, caracoles, había una riqueza. Antes de la llegada de los colonizadores, tenían su centro de toma de masato.

Cuando me contaba mi papá y allí todos mis hermanos mayores, mis cuñados. Después ya todos ellos ya no están. Hasta el 2012,2014, algunos han fallecido y a ellos les he vuelto a preguntar. Cómo se llamaba la aldea allí, les encontraron los evangelizadores, ellos tenían sus costumbres de enterrar a sus muertos. Nuestros lugares que eran prohibidos y ese panteón ya no nos pertenece, lo agarraron los colonos. Los jóvenes de hoy no lo saben, los mayores sí lo sabían.

$3 \quad$ Estas comunidades se las define así: "Las comunidades nativas tienen origen en los grupos tribales de la selva y ceja de selva y están constituidas por conjuntos de familias vinculadas por los siguientes elementos principales: idioma o dialecto, caracteres culturales y sociales, tenencia y usufructo común y permanente de un mismo territorio, con asentamiento nucleado o disperso", de acuerdo con el art. 7 del Decreto Ley N. ${ }^{\circ}$ 20653- "Ley de Comunidades Nativas y de Promoción Agropecuaria de Regiones de Selva y Ceja de Selva”, aprobado el 24 de junio de 1974. 
Mi cuñado último que ya falleció y son pocos los que saben, mi hermano mayor. Los demás no lo saben, son pocos los que saben. Los jóvenes de hoy no saben y tampoco quieren saber y no saben contar a los hijos. (Enrique J. 2021)

En el caso de su labor como docente lo que observa es que:

El propio jefe no tiene una visión y me doy cuenta de que no ama la comunidad, piensa que no es de la comunidad y piensa en vender para comprar un carro. Por eso me dije voy a recopilar la historia porque las personas están aumentándose y las tierras no alcanzan para tantas personas y me preocupa, se pernoctan para trabajar en tierras de otros. Los niños están estudiando y no tienen dinero para seguir educándose y los niños terminan y van a trabajar a la ciudad y se pierden, a veces regresan y otras veces no regresan. No hay renovación de ideas y los jefes siguen los mismos desde hace 20 años, y no hay renovación.

Yo les cuento a los jóvenes porque han regresado y porque no tienen orden, una disciplina para la comunidad. No hay continuidad. ¿`Y qué han hecho? Viene una $\mathrm{ONG}$ y les dice vamos a hacer y aceptan. Les digo ¿qué han enseñado?, y nunca nos han dicho cuánto ha costado el proyecto. $Y$ eso no debe ocurrir. Han capacitado y lo que les digo es que tiene que asumir un cambio.

Ahora la municipalidad dice que hay que enseñar a los nativos como sembrar, pero ya me han enseñado y viene la ONG y le decimos está bien, pero dame las cajas, las cuentas de lo que hemos sembrado. Pero viene otro día y siguen así. $Y$ les digo que vengan y ayuden y trabajamos.

Va a venir muchas propuestas, pero no hay una persona que les pueda liderar. Eso me preocupa y por eso quiero escribir la historia... a veces les cuento. Le entra por este lado y se le sale por este otro lado.

En las razones de Enrique para escribir la "historia de la comunidad" va más allá de si existe o no en los textos escolares, tiene una razón concreta en la evidencia de un conocimiento que se "pierde" y de una generación de padres que ya no cuenta ni sabe contar a los hijos; respecto a "los jóvenes no saben ni tampoco quieren saber" y de unos estudiantes que "le entra por este lado y se le sale por este otro". Como añadió: "no muestran interés de conocer lo que han vivido sus padres y abuelos en el tiempo ancestral”; y además, porque los que saben y sabían esa historia "se están muriendo y no habrá quienes lo cuenten". Esta ha sido su motivación, como lo ha sido antes, lo es hoy y lo será mañana para muchos profesores y aficionados a la historia y leyendas, una de las principales estimulaciones para reconstruir la historia de la comunidad escamoteada en las generaciones de padres e hijos y más aún, negada en la escritura oficial que cuenta una historia nacional sin la historia de la comunidad local. 
Esta inquietud que se convierte en necesidad vital para el docente se repite y recorre el territorio nacional "sin historia de la comunidad"; no obstante, tiene asegurada su vigencia, más aún en los pueblos originarios que en esta reconstitución de sus capacidades y agencia pública, se hace latente y con certeza germinará, porque la historia misma, que se les exige que se cuente como contraparte a la historia oficial — que le niega lugares propios, personajes, hechos y su cultura- demanda que sus intelectuales empiecen a contar con voz propia, su propia historia.

La reconstrucción de la historia de un "pueblo sin historia", sin escritura de los hechos sucedidos vale decir, como la han categorizado para "subalternizarla" respecto a la historia canonizada, ha tenido a la historia oral como una de sus principales herramientas metodológicas. Philippe Joutard (1999) en Esas voces que nos llegan del pasado, presenta un debate en torno a estos asuntos de la reconstrucción de la historia desde la historia oral. Distingue entre otros aspectos, no solo el problema de las fuentes sino también de quien se constituye en el "portavoz de la evidencia" como observa que denomina así al historiador, Raphael Samuel (1978). En el encuentro entre fuente y texto construido emergen al menos tres tipos de subjetividades que Joutard (1999: 246) formula y que veremos más adelante.

Reconstruir la historia de la comunidad implica varios aspectos, entre ellos de dónde empezar a contar, que hechos considerar, el tiempo y el espacio. Quién cuenta, qué historia cuenta. Quién recoge esto que denominan historia y con qué propósito recoge esos hechos que contará como historia. Qué enseñar como hechos de la historia de la comunidad y cómo enseñarla en la escuela. Estos temas, que sin duda pueden ser muchos más, aparentemente menudos obligan a considerar, en el contexto de la Amazonía, si el siglo XVI y los sucesos acaecido en América con la dominación europea puede ser un punto de partida, o la historia de lo que siguió luego, la colonia, expresada en la evangelización cristiana a través de las misiones de los dominicos y franciscanos desde 1635, que incluye los hechos en torno a la rebelión de Juan Santos Atahualpa en 1742, en el actual territorio de la selva central del Perú, o la colonización europea del territorio en 1859 por los alemanes distinguiéndose entre ellos los tiroleses, renanos y bávaros. O los aciagos sucesos alrededor de la explotación y tráfico del caucho, la penetración del cristianismo evangélico, la colonización y migración andina, el conflicto armado interno, entre otros hechos acaecidos a lo largo del siglo XX, o la historia más reciente de los procesos de modernización acelerada en que se encuentran sumidas con las 
tecnologías de comunicación y tal vez con la todopoderosa escuela oficial de careta intercultural bilingüe. Todos estos hechos se encuentran salpicados, algunos con suficiente evidencia y otros omitidos dependiendo qué se narra, quién cuenta la historia y cuándo se cuenta, desde dónde y qué condición tiene el narrador. Lo que sí se reconoce es que todos estos hechos hacen parte de la historia de esta región amazónica y son los que oficialmente se han registrado y que no necesariamente se recuerdan ni están escritos ni se enseñan en la escuela, lugar de preocupación para la reconstrucción de la historia que el docente espera recuperar y enseñar.

El abordaje de la reconstrucción de la historia de la comunidad siendo amplia como se puede colegir en los párrafos precedentes, en esta comunicación se centrará en el texto reconstruido por Enrique considerando cuatro aspectos: el primero referido a las fuentes, quien cuenta y el valor de la fuente; el segundo la información recogida que se considera como la historia de la comunidad; el tercer aspecto, el recopilador y el uso pedagógico de la historia de la comunidad en la escuela, una escuela cuya característica es y está considerada oficialmente como de Educación Intercultural Bilingüe (EIB). Un último aspecto es una reflexión primaria referida a los elementos que subyacen en torno a lo que el "portavoz de la evidencia" narra respecto a la historia de la comunidad, de su comunidad.

\section{Las fuentes: los noshaninkas cuentan}

La recopilación de la información en torno a la historia de la comunidad El Milagro surge como necesidad de enseñanza en tanto ejercicio de docencia, pero precedida por una urgente evidencia de un mundo que se va y es indiferente para las generaciones presentes, adultos, jóvenes y escolares. Por ello se inicia con el registro de datos por informantes familiares y los "hermanos" comuneros, noshaninkas de los cuales cinco de ellos son los referentes, todos residentes en la comunidad cuyas edades fluctúan entre 45 y 85 años; es decir adultos nacidos en el valle de Marankiari que es el lugar donde se ubica la comunidad objeto de la investigación. Las personas requeridas para que cuenten la historia fueron seleccionadas porque se atribuye que viven en la comunidad desde niños, son adultos y han acumulado un saber desde las prácticas cotidianas en la comunidad. Ellos serían las personas idóneas para que cuenten lo vivido en torno a su comunidad. Este procedimiento de selección es usado generalmente por los investigadores como expresión cualitativa y se ajusta a las necesidades de otorgar a las fuentes veracidad respecto a la información que se recoge; en 
ese sentido, esta es una de las primeras certezas que le otorga al investigador que lo que recoge como información es válida. Es la historia verdadera.

Si bien este procedimiento en cuanto a la fuente y la información que se obtiene adquiere validez por las cualidades enunciadas en la selección de los narradores de la historia, tropieza con lo que los historiadores y críticos del método de la historia oral han observado respecto a esta metodología, el asunto de la objetividad y su contraparte la subjetividad como elemento de certeza del dato histórico. El reconocido metodólogo de la historia, Jerzey Topolsky (1982) señala a propósito de las disquisiciones sobre estos asuntos y el hecho histórico que "son tan complejos y variados en su diversidad y relaciones mutuas que la construcción de los hechos es un método inevitable para adquirir un conocimiento simplificado [...] que nos acercamos a la verdad absoluta a través de verdades relativas y aproximadas. [...] ...esto no tiene nada que ver con el subjetivismo" (177). Asimismo, añade que "una fuente solamente proporciona datos sobre un hecho histórico que nosotros construimos, usando además nuestros datos no basados en fuentes" (178). Por lo que "un historiador reconstruye el pasado por medio de la construcción de los hechos históricos, pero de algún modo él es el 'fabricante' de los hechos históricos: construyéndolos los trae a la vida de la sociedad"(179). Exactamente como Enrique procede con respecto a sus fuentes y su objeto de la historia que reconstruye como historia de la comunidad que se presenta en los siguientes apartados y que se consigna tal como lo presenta desde su lógica. ${ }^{4}$

\section{La reconstrucción de la historia de la comunidad E1 Milagro por Enrique Jacobo}

\section{Las motivaciones y la estrategia de recopilación del saber}

Con el objetivo de recopilar la información sobre la historia y los saberes de la comunidad El Milagro, se ha diseñado un plan de actividades para visitar a la comunidad y realizar entrevistas a las autoridades y sabios. Como punto inicial fue asistir a la asamblea comunal y hacer la presentación de la propuesta de investigación sobre la historia de la comunidad. Se presentó la propuesta de visitar a las familias en sus hogares para que nos cuenten acerca de la historia de

$4 \quad$ El texto recogido y reconstruido conserva el orden a excepción de algunos apartados que se han omitido porque se reiteran. Algunos subtítulos se han precisado respetando en todos los casos el sentido de cada sección. Toda la traducción del asháninka al español corresponde a Enrique Jacobo. 
la comunidad, como por ejemplo saber de dónde proviene los pobladores de la comunidad El Milagro, qué hacían antes, dónde y cómo vivían, cuáles eran sus actividades cuando hacían fiestas, cómo aprendían los niños, cómo se organizaban para defender sus tierras antes de la llegada de los colonizadores, por qué no defendieron sus tierras, cómo se organizaron para fundar la comunidad, quién era el que dirigía la comunidad, cómo se denominaba la comunidad, por qué se llama El Milagro, entre otras preguntas. Las respuestas de la gran mayoría de los comuneros expresaron que conocen poco la historia de la comunidad, los cuentos, las tradiciones; y decían "más bien búscale a Don Germán, Héctor y Marcos Luna, son ellos los que conocen”.

\section{Los que conocen en la comunidad}

Don Germán nos contó la historia de la comunidad, las vivencias que tenían desde la antigüedad cuando vivían en el territorio ancestral llamado Inampi asháninka satiposatisanori, que de allí es la procedencia de los pobladores de la comunidad. Cómo llegaron los colonos, cómo trataron a nuestros abuelos. Y muchas otras historias, cuentos, relatos, canciones de nuestra tierra, la forma de vida sana que vivieron muchas familias asháninka en un espacio propio, un territorio ancestral extenso sin límites territoriales que abarcaba desde Shibitsari, todo río abajo del río Satipo hasta el encuentro entre el río Satipo y Panga. La aldea comunitaria que denominaban Inampi asháninka satiposatisanori, un espacio emblemático que lograron construir en medio de cuatro cerros sagrados: Kapiromenishini; Irimakishini; Chakintonini y Morontonini ${ }^{5}$; Juajuato, así como también el lugar de concentración para la toma de ayahuasca que se ubica en el inicio del cerro Irimakishini.

\section{Las costumbres}

Referente a las costumbres que practicaron los asháninka en Inampi asháninka satiposatisanori, en tiempos de la autonomía, fue de establecerse en las playas del río en tiempos de verano donde aprovechaban la pesca y recolección de ranas comestibles llamado abanto. En tiempos de invierno se establecían en las partes altas en los lugares fértiles para aprovechar la caza y la recolección de

5 De los cuatro cerros, el Morontonini es un cerro hundido que está junto al Chakintonini por lo que debe entenderse como un solo cerro, aunque son dos promontorios, y que son parte de los cuatro que se consideran tutelares del valle de Marankiari. 
caracoles, gusanos y hongos comestibles. Hacían fiestas de agradecimiento a la naturaleza con harto masato; cantaban, danzaban, sokareaban, maninkereaban; formaban a los niños con toda la espiritualidad, utilizaban plantas medicinales para ser diestros cazadores y recolectores. Para las niñas también tenían sus propias formas de prepararlas para la vida adulta a través de la celebración de la fiesta de Pankoreanto ${ }^{6}$, una fiesta sagrada con ritualidades de buenos consejos de su madre y abuelos que les llevaría a ser buenas madres y esposas en el tiempo.

La transmisión de la historia y demás saberes a las familias de muchas generaciones fue de boca en boca, no existe registro escrito sobre nuestra historia y conocimientos porque nuestros abuelos no sabían escribir, por esta situación los blancos nos tildaron de ignorantes, incivilizados y otros adjetivos humillantes para asustarnos y nunca reaccionar en defensa de nuestras tierras y saberes.

\section{Tijarini (Panteón ancestral)}

Desde tiempos muy antiguos, los asháninka que vivieron durante años en las riberas del río Satipo, se acostumbraba a enterrar a sus muertos en el cerro llamado tijari, ubicado a cuatro horas de camino, cercano a los cerros más altos de la zona. Pues de acuerdo con la espiritualidad asháninka dice que el espíritu del ser humano puede ser salvado por seres espirituales buenos que habitan en la cima de los cerros. De lo contrario si los muertos son enterrados en las partes bajas, los espíritus malos llegarán antes que los espíritus buenos para llevarlos a la condenación. El tijari se encuentra ahora en la parcela de los colonos, aunque no funciona en la actualidad, pero existe evidencias de una cultura y una historia.

\section{Uso de las plantas}

Las familias de este lugar conocían diversidad de plantas curativas, el bosque era como una farmacia para nosotros, nos cuenta Don Germán. También nos cuenta sobre la existencia de raíces curativas alimenticias y venenosas. E1 evenki y pinitsi, son plantas que están en la casa, hay variedades que se han logrado domesticar.

$6 \quad$ Pankoreanto se dice a las niñas que salen de la choza en el cual la encierran por dos meses cuando inician su menstruación y se celebra con masateo, juegos y mucha carne. 


\section{El territorio comunal ancestral}

El territorio comunal de la comunidad El Milagro se ubica exactamente en el lugar denominado Koibari, en una extensa pampa de tierra fértil, rodeado de cuatro cerros sagrados: Kapiromenishini-Chakintonini, Morontonini, Irimakishini y Juajuatoni, lugar donde siempre pasaban el invierno en la época de la autonomía y dominio territorial ancestral de Inampi asháninka satiposatisanori, conocido en la actualidad como Valle de Marankiari-Satipo. Es una de las doce comunidades nativas reducidas en la época de la invasión y dependencia colonial. Se encuentra en el km 18 de la carretera antigua Satipo-Puerto Ocopa, margen izquierda del río Satipo, distrito y provincia de Satipo, departamento de Junín- Perú, a una hora con movilidad motorizada desde la ciudad de Satipo y una hora de caminata de la carretera hacia la comunidad.

Los limites son: por el Norte con parceleros andinos señores Aquino y Aquiles Aguirre; por el Sur con los parceleros andinos señor Mario Aguirre; por el Este con el riachuelo Shibari; y por el Oeste con el río Sontebenini. En el mapa de ubicación geográfica se puede observar el territorio ancestral asháninka Inampi Asháninka satiposatisanori, que comprende desde el puente E1 Mirador hasta la boca del río Satipo (encuentro entre el río Satipo y el río Panga).

En la antigüedad, es decir en la época de la autonomía o del dominio territorial ancestral de Inampi asháninka satiposatisanori, los asháninka vivieron siempre en el lugar denominado Koibari, que era su segundo espacio de vida. Allí pasaban siempre el invierno todo el tiempo. Consideraban este territorio como un legado ancestral las tierras fértiles y los cuatro cerros sagrados que rodeaban el lugar, pues se creía que allí vivían los seres espirituales, dueños de los animales, aves, gusanos comestibles, caracoles y otros que hacían que las tierras sean fértiles desde siempre. Aquellos cerros eran muy respetados por toda la población, pues conocían su historia, sus bondades y reciprocidad del cuidado natural de las deidades o seres espirituales. La señora Rosa Diaz dice que "Anta otsempiki otishi ari isabikiri Maninkarite, arentite iritake amenakoteri asaikantari kametsa"/ "En la cima de los cerros vivían seres espirituales invisibles que son hermanos nuestros, desde allí nos cuidan para alcanzar el bienestar y buen vivir" (Diaz 2002). 


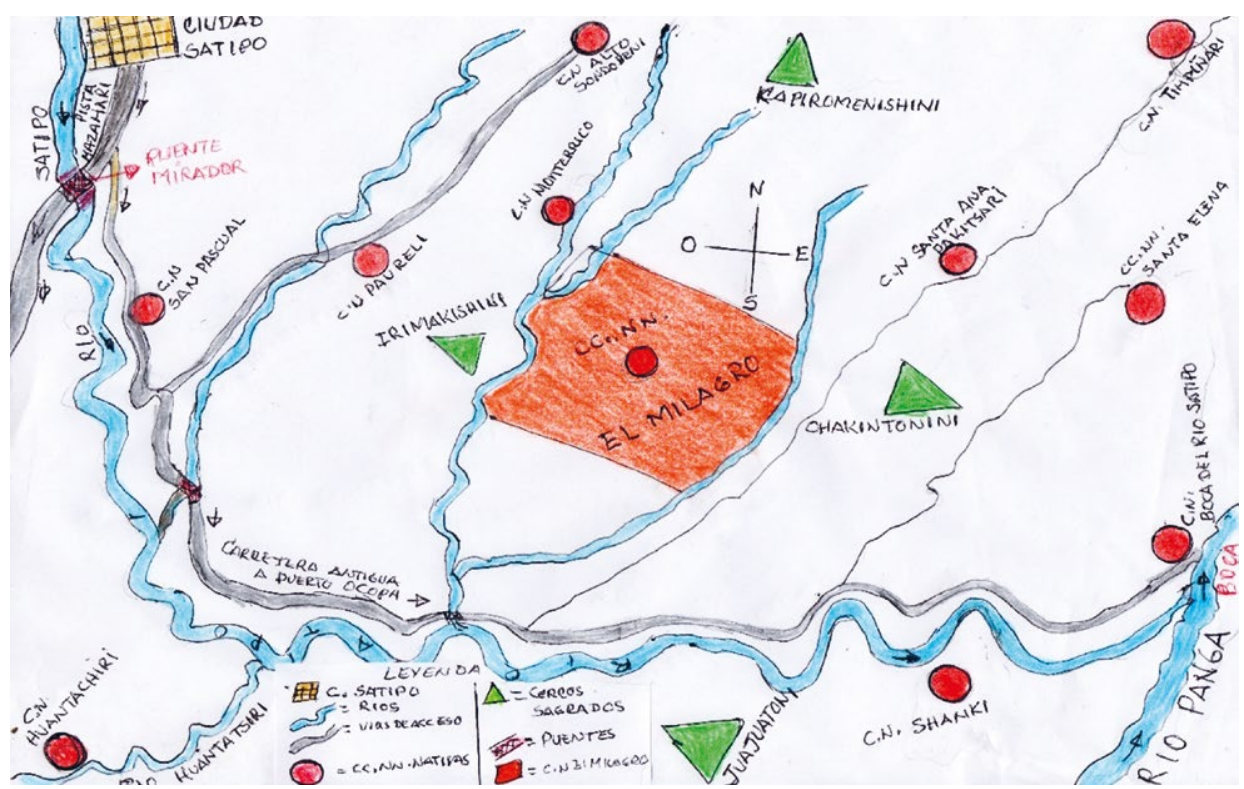

Elaboración: Enrique Jacobo (2020).

Según la tradición asháninka, toda la riqueza que ofrece la tierra está dada para todos los hijos de la naturaleza y todos están obligados a cuidarla y aprovecharla sin mezquindad de nada, sobre todo "compartir" para obtener siempre la bendición; de actuar contrario a ello, la gran riqueza muy pronto terminará.

\section{Proceso histórico de la comunidad asháninka El Milagro: autonomía y dependencia}

\section{Época de la autonomía:}

En la época de la autonomía las familias asháninka eran de su dominio todo el bosque del territorio ancestral denominado Inampi asháninka satiposatisanori, el Gran Valle de Marankiari. Aquí desarrollaron formas muy apropiadas de vida social, cultural y económica no monetaria basado en el cuidado, conservación y aprovechamiento de los recursos naturales en comunión con la naturaleza y seres espirituales, en un vasto territorio que no tenían límites territoriales ni mezquindad con los recursos naturales; logrando así mantener el legado ancestral 
como nampitsi o pueblo con cultura propia y diferenciada en un espacio territorial propio en el interior del bosque.

El espacio de mayor concentración se denominaba Inampi asháninka satiposatisanori, ubicado entre las desembocaduras de los ríos Marankeani y Sontebenini, hoy centro poblado de San Antonio de Marankiari, en toda aquella pampa hasta el inicio del cerro Irimakishini, a 100 metros de la actual institución educativa del referido centro poblado, en una pequeña pampa, fue el lugar de concentración para la toma de ayahuasca. Dicho lugar se denominaba Shimpokirokini.

Las costumbres de las familias asháninka de esa época era vivir en dos lugares a la vez. En el tiempo de verano vivían en las playas del río Satipo, donde aprovechaban la pesca y recolección de ranas comestibles llamado obanto. En la época de invierno se trasladaban en las partes altas, cercanas a los cerros donde aprovechaban la caza y recolección de caracoles, gusanos y hongos comestibles. Estas formas de vida permitieron conservar mejor los suelos productivos y la conservación de los recursos naturales en equilibrio con la naturaleza, logrando con ello mantener siempre el legado ancestral del bienestar y buen vivir durante mucho tiempo. La evidencia más notoria sobre la vida social y cultural que confluyeron sobre la existencia del pueblo asháninka en esta parte de Inampi asháninka satiposatisanori, es el panteón ancestral que se ubica en la parte alta de la actual comunidad El Milagro (aunque no está dentro de su territorio, pero existe y tiene una historia propia). Las demás prácticas sociales culturales, económicas no monetarias se desarrollaron en función a la línea del tiempo circular del pueblo originario; esto nos lleva a entender realidades y costumbres ancestrales practicadas miles de años antes de la llegada de los colonizadores y que es importante considerar y valorar estos conocimiento ancestrales que dieron vida a muchas generaciones del pueblo asháninka para la enseñanza y aprendizaje de los estudiantes en las instituciones educativas bilingües (IEB) de nuestras comunidades en el marco de la inclusión social y de la diversidad cultural del país.

\section{Actividades principales que desarrollaron los asháninkas y las costumbres}

Caza: Ser un diestro cazador era la máxima aspiración de los varones asháninka en épocas anteriores, para ello necesitaba un adiestramiento adecuado y muy riguroso. Los padres y abuelos se encargaban de enseñarles los secretos milenarios de esta importante actividad desde muy temprana edad, pues esta 
actividad le servirá en el futuro para el bienestar y buen vivir. Para concretar y reafirmar este objetivo seguían un ritual siempre y cuando haya cumplido la caza de todos los animales y aves; esta actividad se realiza con un acto ceremonial llamado inicio del comer a los animales que caza y es apadrinado por un anciano y diestro cazador.

Pesca: Esta actividad es parte del saber hacer y ser un diestro pescador, que requiere un trabajo especializado en las diferentes formas de atrapar a los peces como tapando brazos, picándolos con la flecha a peces grandes y chicos, con atarraya, echando cube o Akashi a los ríos pequeños (pesca comunal).

Recolección: Esta actividad también es parte de un conocimiento de saber y ser diestro recolector de productos que prevé la naturaleza, el cual requiere de conocimiento para pedir permiso al "dueño" antes de cosechar lo que no se ha producido con esfuerzo propio. Hacer un acto de compromiso de compartir y tratamiento muy adecuado en el consumo final, especialmente de los "gusanos comestibles" pues la naturaleza cuida y conserva adecuadamente; los demás recursos, como los frutos y caracoles son de libre disponibilidad natural.

Agricultura: Los asháninka son agricultores ecológicos de poca extensión y uso de técnicas adecuadas de diversificación de productos y plantas medicinales. Son diestros cazadores, pescadores, y recolectores conservadores del bosque, "un paraíso" que requiere cuidado, reciprocidad y respeto para alcanzar el bienestar y buen vivir en la tierra. La técnica de la agricultura asháninka consiste en el uso adecuado de las plantas medicinales. Según Marcos Luna: "Para obtener una buena producción de yuca hay que tener en cuenta lo siguiente: Recolectar semillas sanas, saber cortar los nudos, curarla con hierbas y sembrarla en pozas debidamente preparadas con anterioridad en forma de triángulo y hacer dietas" (Luna 2019). También es muy importante la estación lunar para que la siembra tenga una buena producción y las dietas, la técnica de siembra muy popular en el saber asháninka es de forma triangular con asociación de productos diversos que ayudan a que las plantas no sufran el estrés de la soledad.

\section{Festividades: luna y pankoreanto}

Fiesta a la Luna: Mayormente las fiestas de gratitud a la naturaleza se realizaban en la época de luna llena, para aprovechar la luz de la luna y hacer una

7 Se considera gusanos comestibles del bosque a: masoa, shintikeni, charo, shiopa, tinkeni, kontyori, inkorato, poko. 
buena fiesta con danzas de maninkerentsi, sonkareantsi, shikorotantsi, matikantasi. Así compartir la buena comida con la familia. Esta fiesta está relacionada con la gratitud a la naturaleza por las bondades que ofrece, especialmente de la yuca por ser el alimento principal de las personas asháninka.

Pankoreanto (enchozada): Se trata de un mito ancestral para formar buenas mujeres, tanto espiritual y materialmente. $\mathrm{El}$ rito consiste en mantener encerrada bajo una choza en el interior de la vivienda a una niña asháninka que por primera vez tiene la menstruación y que deberá permanecer durante dos lunas cumpliendo dietas y el silencio absoluto, pero trabajando con el hilado del algodón y cumpliendo estrictamente los consejos de su madre y de las abuelas para recibir la bendición de la naturaleza.

Cumplido este periodo de "silencio absoluto", los padres, abuelos y padrinos preparan una gran fiesta del masateo con danzas, maninkerentsi, sonkareo, tamporotantsi, shikorotantsi, matikantasi y con abundante carne, acompañados de juegos especiales para este acontecimiento.

Relatos: La transmisión de los saberes a las nuevas generaciones en el pueblo asháninka se realizaban en base a los relatos orales de la historia, cuentos, mitos, leyendas, cantos, adivinanzas, relacionadas a la espiritualidad, entre ellas están: la historia de la luna, la leyenda de Mapiñaironkaki, historia de la yuca, leyenda de la lluvia, mito de la enchosada, mito del cazador, cuento de yanaite, leyenda de la música asháninka, historia de amatsenka, cuento del viento, mito de ayahuasca, mito de abieri, cuento del tigre, mito de cerros y lagunas sagrados, panteón ancestral.

Uso de las plantas medicinales: La sabiduría de la naturaleza había previsto para los habitantes del bosque una infinidad de plantas, hojas, raíces, frutos para las curaciones de enfermedades en el interior del bosque, es así que las poblaciones originarias que habitaron en el Inampi asháninka satiposatisanori, conocieron muchas plantas, con ellas se curaban de las enfermedades naturales que afectan a las familias.

Sheripiari: Es considerado como sabio en el uso y tratamiento de las enfermedades del cuerpo, es el médico de la familia, a él acudían todas las personas de la comunidad. La forma de curación es en base a la nicotina con la que soplando en la parte afectada: detectaba el mal y adivinaba su origen, para luego proceder su curación con la planta adecuada.

Los contactos espirituales que tenían eran los seres espirituales que vivían en las cimas de los cerros a quienes se les atribuye como seres invisibles dueños 
de la riqueza del bosque y ellos proveían la abundancia del bosque para el beneficio de los seres humanos habitantes del bosque.

\section{Época de la dependencia:}

\section{Evangelización}

Los evangelizadores bajo la prédica de la salvación del alma reunieron a cientos de asháninka en la aldea asháninka Inampi asháninka satiposatisanori. Primero llegaron los franciscanos y luego los evangelistas del séptimo día, ellos fueron los que tergiversaron la cultura del pueblo asháninka. Prohibieron el consumo de los principales alimentos de las familias asháninka considerándolos como inmundos; entre ellos a las huanganas, sajinos, samani, sachavaca, caracoles, gusanos comestibles, peces sin escamas, según testimonio de la abuela María. "Ikanti apani ikemisantakapakeri kemisantinkari, ikantapakeri tsame ankemisanteajatajeta jenoki meka eiro pobayetajari, kemari, samani, shaoni,kitairiki jeri shimape Kari bentakitacha, apinti poyari maniro jeri sima bentakinti, eiroika pikemisanti ari pintakea sharinkabeniki"/ "Mi padre decía que en la aldea Inampi asháninka satiposatisanori los evangelistas evangelizaron para ir al cielo, prohibiendo consumir los animales como sachavaca, sajino, samani, huangana, cupte y pescado sin escama, solo podrás comer venado y pescado con escama” (María 2014).

\section{Colonización}

El primer contacto entre los pueblos originarios y los colonizadores de las tierras asháninka de la selva central, específicamente de Satipo sucedió en el año 1763 (Rodríguez 1991: 12).

A inicios del siglo XX se intensifica la colonización y en la cuenca del río Satipo, territorio ancestral asháninka, con apoyo de los gobernantes de turno, quienes desconocieron la existencia de los pueblos originarios. Los despojaron de sus territorios ancestrales con la más vil humillación y discriminación e imposición cultural muy arraigada. Finalmente los convirtieron en doce comunidades nativas con pocas extensiones territoriales en el interior del territorio ancestral denominado Inampi asháninka satiposatisanori. En la actualidad, estas comunidades y familias, debido al crecimiento poblacional asháninka, viven hacinadas y confundidas de su identidad y cultura, ahora conducidos al hambre y a la extrema pobreza. 


\section{Despojo del territorio ancestral}

Un grupo de familias asháninka conformado por: Karabiri, Shabashi, shirompito, shameiriki entre otros, despojados por los colonizadores de estas tierras del Inampi asháninka satiposatisanori, se fueron al lugar denominado Kiribati y Shibari respectivamente, lugar donde pasaban el invierno durante toda la vida. Allí permanecieron por un buen tiempo hasta que un día vieron a llegar otros colonos (extranjeros) que con título de propiedad en mano expedido por el Gobierno destinado para la hacienda E1 Milagro. Ellos, bajo amenazas de muerte, trataron de despojarlos nuevamente; pero el hacendado se dio cuenta de que los asháninka podrían ser útiles en los trabajos para la hacienda, les concedió tres hectáreas de terreno en el interior de la hacienda bajo condiciones y amenazas; según testimonio del abuelo Juan: "Peeranikametsa isabikajeitini acharineiteni, te intsanetearoni kipatsi, aisati maaroni timayetatsiri, irootake ashijei katsini, inintakanakeero ashitanakeeri: kametsa amenakobenteroeiro amashitsayetitsi"/ "Antiguamente nuestros abuelos vivían tranquilos, los territorios y todo lo que existe aquí era de todos nosotros. Un ser que no se ve, dueño de todo es nuestro padre, él nos concedió este lugar para cuidarla sin mezquindad de nada" (Juan Karabiri 2012).

De esta manera las familias asháninka se quedaron en el interior de territorio de la hacienda, sometidos a los trabajos de campo bajo el sistema de "enganche" hasta que el señor Mazzi, propietario de la hacienda se retiró por enfermedad grave.

\section{Recuperación del territorio, la compran de la hacienda El Milagro}

En la década de 1950, por el año 55, la hacienda había sido abandonada por su propietario el señor Mazzi, a causa de enfermedad. Se fue de la hacienda y nunca más regresó. La hacienda se quedó abandonada por mucho tiempo. Años después, en 1972, los familiares del hacendado llegaron para transferir a terceros, pero no contaban con los documentos de la hacienda. Los asháninka, que no querían perder más sus territorios, decidieron organizarse y comprarla antes que otros los hicieran, pero sin exigir los documentos de por medio del terreno; lo compraron a ciegas, prácticamente. Esto posteriormente les trajo problemas muy serios económicamente, aunque lograron superarlos con la venta de los recursos maderables.

Las familias acordaron comprar la hacienda y como no querían ser comunidad, las dividieron en pequeñas parcelas con título individual. Pero lo 
que no sabían es que la hacienda fue hipotecada al banco con una suma de dinero y para no sufrir de embargo pagaron la deuda a costa de la tala indiscriminada de los árboles maderables.

\section{Fundación de la comunidad}

Antes no era comunidad, para nosotros la comunidad era todo el territorio ancestral de Inampi asháninka satiposatisanori, el bosque era nuestro pueblo, nadie era dueño de nada, "solo existe un dueño" Tasorentsi o Dios, ese es el único dueño. Pero cuando llegaron los colonizadores, nos evangelizaron los misioneros franciscanos, luego los evangélicos que traían un mensaje de salvación. Inicialmente confundió a los asháninka que llegaron de diferentes partes del bosque para seguir al "Gran Salvador" según el mito ancestral que dice: "Algún día llegará un Salvador para llevarse a su hijo de la tierra al gran reino", con este mito las generaciones originarias esperaban siempre toda una vida que esto suceda, y sucedió. Según el testimonio de don Germán.

A nuestros padres lo evangelizaron prohibiéndole el consumo de los principales alimentos sajino, samani, sachavaca, caracoles, gusanos comestibles y pescado sin escama posteriormente llegaron otros colonos que desconocieron nuestra existencia. Nos discriminaron, nos humillaron para quitarnos nuestras tierras imponiéndonos otras culturas y finalmente nos redujeron en doce comunidades con pequeñas extensiones de territorio que en la actualidad nos tienen empobrecidos y con desnutrición crónica por la escasez de los recursos naturales. (Germán 2020)

Es así como los colonizadores de nuestras tierras despojaron a nuestros abuelos de la parte baja de Inampi asháninka satiposatisanori y de las playas del río Satipo; la gran mayoría de las familias se dispersaron. Por su parte, las familias Karabiri (Jacobo), Shamayre, Shirompito, Diaz, Shabashi, y Jorio se dirigieron a la zona de koibari, una zona de Koibashini ${ }^{8}$ lugar donde pasaron siempre el invierno y allí se establecieron. Durante un buen tiempo las familias vivieron tranquilas hasta que un día vieron llegar otros colonos extranjeros que con título en la mano los despojaron nuevamente; sin embargo, ellos no salieron de allí muy a pesar de que los amenazaron con matarlos, finalmente el hacendado se dio cuenta que los asháninka podrían servirle como mano de obra barata en la hacienda por lo que decidió demarcarles tres hectáreas para que vivan allí los campas y que ellos trabajen para la hacienda, así se pusieron

8 Koibashini, es un lugar de tierra fértil con abundancia de koiba, un ave pequeña que es atribuido como el dueño del chamairo, un bejuco que acompañan a la coca para endulzar la boca. 
de acuerdo. Durante muchos años nuestros abuelos trabajaron para la hacienda en el sistema de enganche.

En el año 1980, debido a la necesidad de reivindicación, decidieron formar parte de las organizaciones indígenas que surgieron en defensa del territorio y derecho colectivo, a través de la Central de Comunidades Nativas de la Selva Central (CECONSEC). En asamblea comunal decidieron revertir los títulos individuales para convertirse en comunidad nativa con un solo título. Así se inicia los trámites de reconocimiento.

En el año 1988, la violencia política detuvo el avance de la comunidad, y afectó muy fuertemente nuestra forma de vivir, nos refugiamos en las playas del río Satipo y por dos veces nos atacaron quemando nuestra casas y plantaciones.

Cuando nos refugiamos en las playas del río Satipo, logramos recuperar un pedazo de nuestras tierras allá en Marankiari bajo, lo hicimos uniéndonos con los hermanos de las comunidades de "Santa Ana" y "Tintimari".

\section{Fundación de la escuela y la Educación Intercultural Bilingüe (EIB) ${ }^{9}$}

Desde que la educación oficial llegó en la década de 1960 los estudiantes asháninka de El Milagro estudiaron en escuelas de centros poblados vecinos. Allí fueron inculcados a abandonar su idioma y costumbres de la comunidad, pues significaban un atraso, es así como durante varios años los niños recibieron una educación impuesta y civilizatoria. Recién en el año 2012 se crea la Institución Educativa Bilingüe (IEB). Luego de varios años de gestión comunal hemos luchado bastante con los docentes del centro poblado San Antonio de Marankiari ya que se han opuesto a la creación de nuestra institución educativa (IE). La demora en la creación de este centro educativo fue por la mezquindad de los directores en la IE Ricardo Palma de Marankiari pues presentaban documentos a la UGEL Satipo haciendo ver que la escuela que se pretende crear en la comunidad E1 Milagro no era factible porque estaba a casi cinco minutos de la institución educativa existente en Bajo Marankiari. Pero tampoco a los directores de la UGEL Satipo les interesaba ayudar a las comunidades nativas, ni había interés de las autoridades de la comunidad para exigir el derecho que

$9 \quad$ Conviene precisar las siglas en las instituciones educativas del Perú y de sus principales instrumentos de gestión escolar: Institución Educativa (IE); Institución Educativa Bilingüe (IEB); Educación Intercultural Bilingüe (EIB); Unidad de Gestión Educativa Local (UGEL) su jurisdicción abarca una provincia generalmente. Plan Anual de Trabajo (PAT); Proyecto Educativo Institucional (PEI). 
les corresponde como comunidad y el de los estudiantes. Según los testimonios de los padres de familia de la IEB, el jefe de la comunidad Don Marcos Luna trabajo muy bien para hacer realidad la creación de la IEB Antami.

\section{Aplicación en la escuela EIB}

\section{Metodología}

Para la enseñanza y aprendizaje de los niños en la EIB, partimos desde la línea del tiempo circular en el cual se encuentra las memorias y la historia del tiempo que vivieron nuestros antepasados en la época de la autonomía, así como también de las costumbres vivas practicadas en un vasto territorio de Inampi asháninka satiposatisanori, el "Valle de Marankiari". Con la llegada de los colonizadores, las prácticas culturales fueron desplazadas por otras culturas.

En la escuela se trabaja en base a proyecto de aprendizaje con temáticas de la historia, cuentos, relatos y demás saberes y conocimientos de la comunidad. A partir de esta línea del tiempo construimos con los padres de familia el calendario comunal donde identificamos las actividades que realizan las familias en la comunidad. A partir de allí elaboramos los proyectos de aprendizaje con una duración de una semana, 15 hasta 30 días.

Las actividades programas con los padres de familia son adecuadas e insertadas en el Plan Anual de trabajo (PAT) y el Proyecto Educativo Institucional (PEI) de la IEB, las cuales son instrumentos de gestión escolar adecuaciones a la programación Curricular Nacional. El trabajo escolar con los estudiantes es mayormente de investigación de acuerdo con la edad y grado de los niños.

En la estrategia de aprendizaje escolar también hemos visto la necesidad de incorporar a los mayores y sabios de la comunidad a fin de que ellos sean los protagonistas del aprendizaje de los conocimientos practicados durante mucho tiempo en el pueblo asháninka. Estos sabios han contribuido al cuidado y conservación de la naturaleza y el medio ambiente a lo largo del tiempo y dieron vida a muchas generaciones en el interior del bosque y del pueblo asháninka transmitidas por medio de la oralidad; ellos comparten sus experiencias vivas de un amplio conocimiento ancestrales sobre todo la historia de la cuenca Inampi asháninka satiposatisanori, así también conocimientos de la comunidad, sobre sus procesos históricos y de organización como comunidad nativa E1 Milagro y del porqué de su nombre. 
Asimismo, sobre los conocimientos en el uso de las plantas medicinales para el tratamiento de las enfermedades, los secretos para ser diestro cazador de animales, aunque en la comunidad ya no existen animales para cazar porque la madre de ellos, que es el bosque, fue depredada sin piedad alguna, los animales se fueron a las reservas comunales o se extinguieron. Pero es necesario hacer uso de estos conocimientos e incorporarlos en las áreas curriculares para el aprendizaje de los estudiantes en la Institución Educativa Bilingüe que contribuirá a que los estudiantes conozcan la historia de su lugar de origen y se identifiquen con la cultura de su comunidad logrando afianzar sus aprendizajes a partir de lo que ven, oyen y tocan con sus manos haciendo que la educación sea más integradora, pertinente y con valores que contribuyan al desarrollo integral de la comunidad, región y del país en general.

La práctica cotidiana con los estudiantes en la IEB sobre los hallazgos encontrados en el quehacer de la comunidad se torna interesante sobre todo con el apoyo de los sabios y la comunidad en general, toda vez que los conocimientos de la comunidad o de los pueblos originarios no están registrados en documento alguno. Sin embargo, los pobladores más antiguos cuentan, es voz propia y los estudiantes escuchan una historia de vida de un pueblo originario que vivió en medio del bosque, desarrollando formas de vida muy apropiada y de conservación de la naturaleza, practicando un acervo cultural propio, legado de nuestros padres y abuelos desde siempre.

Con la llegada de los colonizadores, estos conocimientos fueron estigmatizados y desplazados con otras culturas que terminaron cambiándoles la historia de "abundancia" a "extrema pobreza" de "dueños" legítimos de un vasto territorio ancestral, a "pequeñas comunidades nativas" con escasez de recursos naturales que conducen al hambre y la desnutrición crónica en la actualidad.

Existen diversas estrategias para la enseñanza de los estudiantes en la EIB programadas en proyectos de aprendizaje basados en cuentos, cantos, mitos, elaboración de las artesanías, la pesca, caza y recolección de frutos comestibles entre otros conocimientos propios de la comunidad, pero también integramos los aprendizajes diversos de la educación oficial y las nuevas tecnologías de la información.

Nuestra labor con los niños en EIB se basa en la investigación de pequeños detalles de la cotidianidad de la vida real que los invita a conocer la realidad de su contexto comunitario y a construir su formación escolar centrada en una 
sociedad crítica, creativa, participativa, horizontal, equitativa, democrática y recíproca desde la mirada de los pueblos indígenas de la Amazonía.

Los padres de familia y comunidad en general están de acuerdo con esta perspectiva educativa que fomenta valores de identidad cultural de los pueblos y promueve el aprendizaje pertinente y autónomo de los estudiantes.

\section{Conclusiones}

Siendo nuestro propósito conseguir información etnográfica sobre la historia de la comunidad asháninka El Milagro, para conocer a profundidad los sucesos ocurridos en el proceso de la historia de vida de la comunidad y confirmar la existencia milenaria del pueblo asháninka en un vasto territorio en la cuenca del río Satipo, como un legado ancestral y conocer las prácticas culturales que realizaban en tiempos de la autonomía y qué sucedió en la época de la colonización, cuáles fueron sus reacciones en defensa de sus territorios.

En consecuencia, el presente estudio nos permitió conocer procesos de evangelización, colonización y reducción de los habitantes originarios de un vasto territorio ancestral a pequeñas comunidades nativas empobrecidas por falta de los recursos naturales y dependencia del mercado.

\section{Discusión}

Tratamos sobre el saber y la historia de la comunidad asháninka El Milagro, una de las doce comunidades reducidas con pequeñas extensiones territoriales en el territorio ancestral Inampi asháninka satiposatisanori, el Valle de Marankiari, donde los pobladores de las comunidades se encuentran empobrecidas por carencia de los recursos naturales. Para sobrevivir trabajan para otros como jornalero y con bajos salarios que nunca permitieron y permitirán avanzar en la educación de sus hijos.

Nos preocupa que las familias asháninka de las comunidades no hayan logrado ubicarse en el contexto de la globalización con el valor real de su identidad porque no han tenido la oportunidad de formarse adecuadamente en su propio lenguaje y con una educación con valores desde el saber y la historia de la comunidad. 


\section{Notas preliminares en torno a la historia de la comunidad reconstruida por Enrique}

Con relación a las fuentes conviene retornar a las advertencias de Joutard (1999) en torno a la constitución de archivos orales, señala que estos son provocados y construidos. Además, ha de considerarse que la información que se recoge proviene de la memoria y se convierte en archivo oral, por lo que el documento debe tener en cuenta los procedimientos de construcción, los cuales están mediados por las situaciones de la subjetividad en que se ven envueltas. La primera de ellas expresa la subjetividad del autor entrevistado; la segunda subjetividad, se genera en la lectura que se hace del texto convertido en documento recogido; la tercera, precisa que "el archivo no solo nace sino que se construye en el diálogo entre entrevistador y entrevistado" (Joutard 1999: 246).

Si como expresa Enrique, son pocos los que recuerdan y lo que se recuerda proviene de la memoria ante la ausencia de documentos escritos, la evocación oral como testigo o depositario de la tradición se constituye en el vehículo que moviliza la memoria para reconstruir los hechos de un pasado fenecido pero latente a través de las costumbres, más que de los hechos sucedidos de manera sucesiva, unilineal en el tiempo, que se expresa en la recopilación de la historia de la aldea ancestral del valle de Marankiari, como se puede colegir en la narración que construye el "portavoz de la evidencia", Enrique.

Un segundo aspecto tiene como referencia el tema propuesto por el investigador que delimita y establece los parámetros a contar y que en la presentación emerge como la lectura de lo que el entrevistador quiere registrar para luego comunicar, el mismo que está signado por su condición docente y el mandato de la enseñanza que desea imprimir y recrear como aprendizaje que le sea significativo no solo en el aula para sus estudiantes, sino también para sus hermanos e hijos de la comunidad.

Del mismo modo, la historia que recoge ha acudido a la memoria del padre, madre, parientes y hermanos de la comunidad presentes y ausentes, porque recurre al recuerdo de los que no están y a falta de datos y presencia física en la reconstrucción, construye el dato para completar la historia que debe calzar con sus deseos de tener una historia "verdadera". Este proceso de negociación del dato se da en dos niveles: el primero entre entrevistador y entrevistado en torno a una idea de hecho histórico que refrende una sola versión, que será la verdad por revelar; y el segundo, entre el investigador y la memoria del entrevistado ausente a quien se le trae al presente a través de la evocación del hecho histórico 
que refrenda la historia ausente y presente como verdad, que es como se erigirá en la reconstrucción de la historia.

Respecto a los tópicos del tema de la historia de la comunidad, estos expresan sin duda el proceso de negociación entre la necesidad de construir una historia de y para la comunidad, que sirva a los intereses de salvaguardia de la identidad, que tenga como destino el fortalecer el derecho, la vigencia y los mecanismos de defensa del territorio y la cultura ancestral del cual se siente responsable el investigador en su condición de docente originario; y de otro lado, la necesidad de testificar como memoria de la comunidad que se encuentra entre el recuerdo y el olvido de los entrevistados, miembros de la comunidad que testifican para la reconstrucción de la vida y cultura de la comunidad que se convertirá en historia oficial ante el requerimiento del entrevistador docente originario, que como también ha advertido Jourtard (1999:248-249), para el caso del reconstructor de la historia oral cuando se es extraño a la comunidad por más que se haya ganado la confianza suficiente con sus interlocutores, la omisión o secretos que no se brindan se pueden dar como no, es decir las circunstancias de dar y obtener información varían. En el caso de un miembro de la misma comunidad, como Enrique, también puede aplicarse: serán las circunstancias de los hechos a revelar, los personajes involucrados en los acontecimientos, la utilidad práctica o sentimental, o familiar o social las que puedan determinar obtener la información a historizar. Es decir, nada garantiza que al final esa sea la versión "verdadera" de la historia por más que quien recoge sea un originario de la comunidad. La relatividad del dato entonces depende de estos factores y subjetividades que emergen en el encuentro entre memoria e historia de vida de la comunidad.

De esta manera, como se puede observar en los tópicos que se proponen como historia de la comunidad, esta se constituye a partir de algunas características: los grandes temas de la historia giran en torno al territorio y la evocación de la ancestralidad y junto a ella más que el dato de cuándo y quiénes, predomina el paisaje, los linderos y la nostalgia de un tiempo que se añora y reivindica como buen vivir. En tanto historia desde la memoria, es posible distinguir dos aspectos: el primero es el asociado a su condición étnica, el referente de la ancestralidad con la que se presenta y asume autoridad el entrevistador, que es originario de la comunidad, le imprime una temática que demanda de sus hermanos, sus noshaninka, por lo que las costumbres emergen como parte consustancial y en armonía con el territorio y los "dueños de la riqueza del bosque". La historia de la comunidad no son los datos en sí colocados en una línea del tiempo unilineal, 
aunque con fines pedagógicos se los presente en dos segmentos diferenciados de autonomía y dominación que deviene del aprendizaje académico, pero cuando inquiere en la comunidad, ella se diluye y emerge las costumbres como prácticas cotidianas de la reproducción de la vida biológico social y las de carácter sacro que requiere de ceremonias y ritos de encuentro ancestral que le deviene de su condición étnica, cultural y espiritual, el de ser y reconocerse hombre, naturaleza y divinidad que se puede observar en los testimonios de quienes narran, de manera muy breve, cuando se les pide que cuenten la historia de los ancestros: es el territorio, el bosque originario, el paisaje con sus cerros tutelares y los ríos, los animales y las plantas del bosque, los seres invisibles y las divinidades estelares, luego las costumbres, las ceremonias y el oficiante sheripiari en torno a ellas.

En un segundo segmento de presentación de la historia de la comunidad se organiza un relato unilineal del tiempo, que remite más que al recuerdo de los comuneros, es la data, son los sucesos que se recoge, que se reconstruye y acomoda para hacerla calzar con los hechos que se recuerdan desde la condición de acceso a la información canónica. En ella sobresale en el recuerdo la colonización y la evangelización entre los hechos más notorios, aunque los datos son imprecisos en los relatos seleccionados, pero se incide en un hecho fáctico, el primero es que la evangelización misionera franciscana está presente en el recopilador más que en la memoria de la comunidad, sin embargo la de carácter evangélica, aquella de mediados del siglo pasado emerge como la que les impuso prohibiciones y otros cultos y les quitaron las creencias y prácticas de vida, de armonía con la vida alrededor del bosque y del "dueño de todo" Tasorentsi. El otro hecho relevante es la colonización, que les despojó del territorio como lugar sagrado y de reproducción de la vida y costumbres como cultura viva. En ambos casos se trata de actos de cercenamiento de lo esencial de la vida, de la cultura asháninka.

Conviene reparar en varios temas que emergen de lo hasta aquí comentado y son los tópicos ausentes que no se expresan no porque se carezca de memoria, sino porque no se ha enfatizado como tema sugerido de exploración o se tiene escasa información, o tal vez las personas entrevistadas desconocen o se olvida porque no le es relevante o no se habla por dolor que le ocasiona ese recuerdo, o también porque implica borrar o destruir las huellas o que permanezcan en reserva como han observado los especialistas respecto al tema del olvido, como señala Ricoeur (2004): "bajo los pasos de la memoria y de la historia se abre, pues, el dominio del olvido, dominio dividido contra sí mismo entre la amenaza de la destrucción definitiva de las huellas y la seguridad de que siempre permanecen en reserva los recursos de la anamnesis"(:14). Entre ellos se pueden mencionar a 
manera de ilustración la ausencia de referencia al recuerdo de la rebelión de Juan Santos Atahualpa de 1742 y que se ha incorporado como tópico de la memoria en otras zonas de la selva central o la referencia a la condición de autodefinirse como un pueblo "guerrero" en los estudios de Espinosa (2012); aunque el mismo autor señala que “Sin embargo, a pesar de autodefinirse como 'pueblo guerrero', no es una sociedad que se defina exclusivamente a partir de la experiencia de la guerra, como ocurre con otras sociedades amazónicas (como la awajún o achuar)"(2012: 286). Es más, añade que la imagen como pueblo guerrero desde mediados del siglo XX se consolida y los estudios de etnografía e investigaciones etnohistóricas de esos años en adelante, confirman estas cualidades guerreras; estos investigadores "coinciden en señalar que la guerra para los asháninkas no constituye el elemento central de su vida” (2012: 287-288).

En el recojo de datos para la construcción de la historia de la comunidad El Milagro esta referencia está ausente y lo que sí se reitera es el despojo de sus tierras y la recuperación de estas a través de la estrategia de conversión en comunidad nativa al amparo de la legislación y la compra de terrenos a la familia que los despojó; pero el énfasis de esta condición de "guerrero", tal vez se exprese como defensor de los derechos a la vida en el territorio ancestral bajo la afirmación de su cultura y que denominan "buen vivir". Asociada a ella está el mito que "Algún día llegará un Salvador para llevarse a su hijo de la tierra al gran reino" que tiene acaso relación no solo con la evangelización misionera y evangélica sino también con esta idea de redención ante el despojo de su territorio y cultura, para no referirnos a milenarismos y mesianismos que no se explicitan con esa denominación en la historia reconstruida y que tiene también un largo asedio bibliográfico que aquí no se explora. En el caso de la evangélica, puede asociarse a esa "promesa liberadora" que redime y restituye como lo han reportado para el valle de Tsiriari, Alva y Castillo (2021: 141-147).

Un último aspecto por considerar es el destinatario inmediato de la reconstrucción de la historia de la comunidad y su tratamiento en el aula de la institución educativa bilingüe, en el marco de la implementación estatal de la política de Educación Intercultural Bilingüe (EIB) que la escuela se encuentra registrada e inmersa en lo curricular como en la gestión institucional. El procedimiento metodológico describe las estrategias que todo docente realiza para el desarrollo de capacidades a través de proyectos de aprendizaje: incorporar el saber local, diversificar por áreas curriculares, participación de los que saben o sabios de la comunidad. Tal vez lo más valioso es la aplicación bajo la lógica de aprendizaje de enseñar la historia de la comunidad desde lo que se denomina 
el ciclo del tiempo circular que no se explicita, pero que tiene como referente el calendario comunal que se construye con la participación de los padres de familia y de acuerdo con las necesidades de reproducción de la vida y cultura local del pueblo asháninka.

Si bien es cierto, experiencias de construcción de conocimiento como los que ha emprendido Enrique, recupera la condición de productor de conocimiento en la función docente, que es lo que se espera como responsabilidad profesional, requiere de mayor aliento tanto de la comunidad originaria como de los espacios formativos en curso para repensar los enfoques, que sin duda se inscriben en lo que CEPAL (2014) ha caracterizado como posmodernista en tanto la recuperación de la historia de la comunidad podría ubicarse en esta perspectiva que "buscaría un trato igualitario de las distintas culturas y lenguas en contacto" en tanto se propone "abordar las consecuencias de la colonización en el ámbito de las competencias lingüísticas. Pero más allá de ello, de redefinir las relaciones hasta ahora desiguales entre los pueblos originarios y las sociedades de los Estados en que dichos pueblos se encuentran" (2014: 288). Es en este espacio de las políticas de interculturalidad en educación que se relacionan con las demandas de políticas de derechos humanos que los pueblos originarios han emprendido, pero que se ven afectadas por las desigualdades educativas y los condicionantes socioeconómicos y políticos de cada país y al interior de cada uno de ellos, no obstante que se suscriben y declara en el nivel de políticas de educación intercultural estas distan de lo que finalmente se aplica, como remarca el mismo documento de CEPAL. Aun así, las iniciativas deben ser fortalecidas desde las bases de alianzas institucionales de las organizaciones y el ámbito académico, que promueva investigaciones en el que docentes como Enrique indaguen y construyan su propia historia de la comunidad y se constituyan en el "portavoz de la memoria" de su pueblo originario. 


\section{Referencias bibliográficas}

Alva, Jacobo y Jackeline Castillo J. "Memoria del conflicto armado interno en los asháninkas evangélicos y la promesa liberadora”. En: O. Espinosa, S. Romio y M. Ramírez Colombier (editores). Historias, violencias y memorias en la Amazoní. Lima: Pontificia Universidad Católica del Perú, 2021, pp. 117-149.

Comisión Económica para América Latina - CEPAL. Los pueblos indígenas en América Latina. Avances en el último decenio y retos pendientes para la garantía de sus derechos. Santiago de Chile: CEPAL, 2014.

Espinosa, Oscar. La violencia y la historia asháninka: de Juan Santos Atahualpa a Sendero Luminoso. En: J.-P. Chaumeil, F. Correa, R. Pineda (editores). El aliento de la memoria: Antropología e Historia en la Amazonía Andina. Bogotá: Instituto Francés de Estudios Andinos - IFEA, Universidad Nacional de Colombia, 2015, 284-301.

Joutard, Philippe. Esas voces que nos llegan del pasado. Buenos Aires: Fondo de Cultura Económica, 1999.

Ricoeur, Paul. La memoria, la historia y el olvido. Buenos Aires: Fondo de Cultura Económica, 2004.

Rodríguez, Elizaldo. Satipo y la real historia de los colonos fundadores. Satipo: Editorial Felic, 1991.

Topolsky, Jerzy. Metodología de la historia. Madrid: Ediciones Cátedra, 1982.

\section{Legislación}

Decreto Ley N. 20653 - "Ley de Comunidades Nativas y de Promoción Agropecuaria de Regiones de Selva y Ceja de Selva”, aprobado el 24 de junio de 1974. 


\section{Entrevistas}

Azua, Alejandrina. 79 años. (2020, noviembre).

Díaz, Rosa. 80 años aprox. (2002, enero).

Díaz, Germán. 73 años aprox. (2020, junio y julio).

Díaz, María. 76 años aprox. (2014, noviembre).

Karabibri, Juan. 85 años aprox. (2012, setiembre).

Luna, Marcos. 45 años aprox. (2019, abril). 